\title{
The effect of impregnation strategy on methane dry reforming activity of Ce promoted $\mathrm{Pt} / \mathrm{ZrO}_{2}$
}

\author{
Şeyma Özkara-Aydınoğlu ${ }^{a}$, Emrah Özensoy $^{b}$, A. Erhan Aksoylu ${ }^{a, *}$ \\ ${ }^{a}$ Department of Chemical Engineering, Boğaziçi University, 34342 Bebek, Istanbul, Turkey \\ ${ }^{\mathrm{b}}$ Department of Chemistry, Bilkent University, 06800 Bilkent, Ankara, Turkey
}

\section{A R T I C L E I N F O}

Article history:

Received 25 March 2009

Received in revised form

2 September 2009

Accepted 2 September 2009

Available online 27 October 2009

\section{Keywords:}

$\mathrm{CO}_{2}$ reforming of methane

Dry reforming of methane

$\mathrm{Pt}-\mathrm{Ce} / \mathrm{ZrO}_{2}$ catalysts

Synthesis gas

\begin{abstract}
A B S T R A C T
Dry reforming of methane has been studied over $\mathrm{Pt} / \mathrm{ZrO}_{2}$ catalysts promoted with Ce for different temperatures and feed compositions. The influence of the impregnation strategy and the cerium amount on the activity and stability of the catalysts were investigated. The results have shown that introduction of $1 \mathrm{wt} . \% \mathrm{Ce}$ to the $\mathrm{Pt} / \mathrm{ZrO}_{2}$ catalyst via coimpregnation method led to the highest catalytic activity and stability. $1 \mathrm{wt} . \% \mathrm{Ce}-1 \mathrm{wt} . \% \mathrm{Pt} / \mathrm{ZrO}_{2}$ catalyst prepared by sequential impregnation displayed inferior $\mathrm{CH}_{4}$ and $\mathrm{CO}_{2}$ conversion performances with lowest $\mathrm{H}_{2} / \mathrm{CO}$ production ratios. $1 \mathrm{wt} . \% \mathrm{Ce}-1 \mathrm{wt} . \% \mathrm{Pt} / \mathrm{ZrO}_{2}$ catalyst prepared by coimpregnation showed the highest activity even for the feed with high $\mathrm{CH}_{4} / \mathrm{CO}_{2}$ ratio. The reason for high activity was explained by the intensive interaction between Pt and Ce phases for coimpregnated sample, which had been verified by X-ray photoelectron spectroscopy and Energy Dispersive X-Ray analyses. Strong and extensive $\mathrm{Pt}-\mathrm{Ce}$ surface interaction results in an increase in the number of $\mathrm{Ce}^{3+}$ sites and enhances the dispersion of Pt.
\end{abstract}

(c) 2009 Professor T. Nejat Veziroglu. Published by Elsevier Ltd. All rights reserved.

\section{Introduction}

Catalytic carbon dioxide reforming of methane (dry reforming, DR) [Eq. (1)], which converts two gases, $\mathrm{CH}_{4}$ and $\mathrm{CO}_{2}$, with high global warming potential to valuable synthesis gas (syngas), a mixture of $\mathrm{CO}$ and $\mathrm{H}_{2}$, has received considerable attention in recent years [1-3].

The DR process becomes industrially advantageous compared to steam reforming (SR) [Eq. (2)] or partial oxidation (POX) [Eq. (3)] in syngas production since $\mathrm{H}_{2} / \mathrm{CO}$ product ratio is close to $1 / 1$, which is suitable for further use in the production of oxygenated compounds as well as FischerTropsch synthesis for production of liquid hydrocarbons $[2,4,5]$.

$\mathrm{CH}_{4}+\mathrm{CO}_{2}=2 \mathrm{CO}+2 \mathrm{H}_{2}, \Delta \mathrm{H}_{298}^{0}=+247 \mathrm{~kJ} \mathrm{~mol}^{-1}$

$$
\begin{aligned}
& \mathrm{CH}_{4}+\mathrm{H}_{2} \mathrm{O}=\mathrm{CO}+3 \mathrm{H}_{2}, \Delta \mathrm{H}_{298}^{0}=+206 \mathrm{~kJ} \mathrm{~mol}^{-1} \\
& \mathrm{CH}_{4}+1 / 2 \mathrm{O}_{2}=\mathrm{CO}+2 \mathrm{H}_{2}, \Delta \mathrm{H}_{298}^{0}=-38 \mathrm{~kJ} \mathrm{~mol}^{-1}
\end{aligned}
$$

The major drawback of DR is that elevated temperatures are required to reach high conversion levels due to highly endothermic nature of the process. These severe operating conditions result in deactivation by coke deposition [6-8] and/or sintering of the metallic phase and support [9-12]. Thus, it is desired to develop effective DR catalysts exhibiting high activity and selectivity as well as good stability in the syngas production. Coke is formed mainly by two reactions, methane decomposition [Eq. (4)] and carbon monoxide disproportionation [Eq. (5)]. The former is an endothermic reaction and favored at higher temperatures and lower pressures, whereas the latter is exothermic and favored at lower temperatures and higher pressures [13].

\footnotetext{
* Corresponding author. Tel.: +90 212359 7336; fax: +90 2122872460 .

E-mail address: aksoylu@boun.edu.tr (A.E. Aksoylu). 0360-3199/\$ - see front matter ( 2009 Professor T. Nejat Veziroglu. Published by Elsevier Ltd. All rights reserved. doi:10.1016/j.ijhydene.2009.09.005
} 
$\mathrm{CH}_{4}(\mathrm{~g}) \rightarrow \mathrm{C}(\mathrm{s})+2 \mathrm{H}_{2}(\mathrm{~g}), \Delta \mathrm{H}^{0}=75.2 \mathrm{~kJ} \mathrm{~mol}^{-1}$

$$
2 \mathrm{CO}(\mathrm{g}) \rightarrow \mathrm{C}(\mathrm{s})+\mathrm{CO}_{2}(\mathrm{~g}), \Delta \mathrm{H}^{0}=-173.0 \mathrm{~kJ} \mathrm{~mol}^{-1}
$$

Catalytic performance of supported metallic catalysts for $\mathrm{DR}$ reaction is affected by several factors such as the nature of the metal, the support type as well as the conditions for the catalyst preparation and pretreatment $[12,14,15]$. It is reported in literature that support has a significant effect on both catalytic activity and stability $[8,13,16]$. It has been shown that certain supports are able to provide oxygen to the metal during the reaction and, by this way, suppress carbon deposition [16-20]. Thus, oxides with high oxygen exchange capacity and mobility are expected to be good candidates as supports for the DR reaction. When compared to irreducible oxides, such as $\mathrm{Al}_{2} \mathrm{O}_{3}$ or $\mathrm{SiO}_{2}[4,8,16,21]$, the use of $\mathrm{ZrO}_{2}$ can result in attractive process benefits owing to its redox behavior, surface acidity, reducibility and high thermal stability.

Good activity and stability characteristics of $\mathrm{Pt} / \mathrm{ZrO}_{2}$ catalysts were reported in several papers $[4,5,22]$. Coke, which may cover the active sites, is hardly formed on $\mathrm{Pt} / \mathrm{ZrO}_{2}$ resulting in stable activity for long periods of time. In earlier studies $[5,22,23]$, it has been proposed that the reaction involves decomposition of $\mathrm{CH}_{4}$ on Pt particles leading to the formation of $\mathrm{H}_{2}$ and partially dehydrogenated species $\left(\mathrm{CH}_{\mathrm{x}}\right)$, and dissociation of $\mathrm{CO}_{2}$ into $\mathrm{CO}$ and $\mathrm{O}$ on the support. The oxygen formed during the dissociation of $\mathrm{CO}_{2}$ can subsequently oxidize the $\mathrm{CH}_{x}$ species. The balance between the rate of decomposition of $\mathrm{CH}_{4}$ on metal particles and the rate of its oxidation by the dissociated $\mathrm{CO}_{2}$ determines the overall stability of the catalyst.

Previous studies $[5,24,25]$ conducted over commercial or coprecipitated catalysts have shown that the addition of promoters to the $\mathrm{ZrO}_{2}$ support results in increased activity as well as stability for the reforming reactions and that the addition of $\mathrm{Ce}$ to the $\mathrm{ZrO}_{2}$ support resulted in significant improvement in the stability, with no decrease in neither $\mathrm{CH}_{4}$ nor $\mathrm{CO}_{2}$ conversions.

Particularly, noble metal catalysts containing ceria as a promoter increase the catalytic reactivity in the oxidation reactions of different hydrocarbons [26-28] and enhance the performance characteristics of three-way catalysts used in elimination of pollutants in automobile exhaust [29-31]. The unique acid-base and redox properties of ceria influence the dispersion of the active metals on the support as well as oxidation and reduction cycle of noble metals [32,33]. The oxygen vacancies at the metal-oxide interface of reduced ceria, leading to high oxygen storage capacity, suppress coke formation [32,34].

The purpose of the present work is to develop effective Pt based DR catalysts supported on zirconia. In order to develop catalysts with enhanced performance properties, $\mathrm{Ce}$ is used as a promoter, which is added through conventional impregnation method. The main intention is to have a high dispersion of the cerium on the surface of the support rather than to have it incorporated in the skeletal bulk structure of the catalyst, such as the catalysts reported in the literature prepared by coprecipitation [24]. To determine optimal combination of reaction conditions and catalyst composition leading to superior productivity and selectivity; impregnation strategy, cerium amount, reaction temperature and $\mathrm{CH}_{4} / \mathrm{CO}_{2}$ feeding ratio were used as parameters during the performance tests. The reduction characteristics of freshly calcined samples and the amount of coke deposited on the used catalysts were determined by thermogravimetric and differential thermal analyses (TGA/DTA). The extent of interaction between Pt and Ce components during the preparation procedures was investigated by determining the amounts of metallic and oxide phases of Pt and Ce via X-ray photoelectron spectroscopy (XPS). The Pt and Ce dispersions on the catalyst surfaces were studied by scanning electron microscopy (SEM) and energy dispersive X-ray (EDX). The relation between the catalyst activity and Ce redox ability is discussed in detail.

\section{Experimental}

\subsection{Catalyst preparation}

$\mathrm{Pt} / \mathrm{ZrO}_{2}$ and $\mathrm{Pt}-\mathrm{Ce} / \mathrm{ZrO}_{2}$ catalysts were prepared by classical impregnation method. $\mathrm{ZrO}_{2}$ support was bought from Alfa Aesar. The support was calcined at $1073 \mathrm{~K}$ for $4 \mathrm{~h}$ in muffle furnace prior to the addition of the metals. Although this heat treatment caused a reduction in the BET surface area, from 93 to $16 \mathrm{~m}^{2} / \mathrm{g}$ after calcination, thermal stability of the support was improved.

$1 \mathrm{wt} . \% \mathrm{Pt} / \mathrm{ZrO}_{2}$ was prepared by pore volume impregnation of aqueous tetraammineplatinum nitrate solution. The Pt-Ce/ $\mathrm{ZrO}_{2}$ catalysts were prepared either by coimpregnation, in which aqueous precursor solutions of Pt (tetraammineplatinum nitrate) and Ce (cerium nitrate) were impregnated together onto $\mathrm{ZrO}_{2}$ with defined concentrations in order to obtain the fixed Pt load of 1 wt.\% and Ce loads of 1 and 5 wt.\%, or by sequential impregnation, in which impregnation of aqueous cerium nitrate solution was followed by heat treatment at $773 \mathrm{~K}$ for $4 \mathrm{~h}$ in muffle furnace and then by impregnation of aqueous tetraammineplatinum nitrate solution. Each impregnation step was conducted under vacuum. In all catalysts, the precursor solutions $(0.5 \mathrm{ml} / \mathrm{g}$ support $)$ with calculated concentrations were added via a peristaltic pump. After the impregnation step, the samples were dried overnight at $383 \mathrm{~K}$ (Table 1).

\subsection{Catalyst characterization}

All catalyst samples and the support were characterized by temperature-programmed reduction (TPR) tests for their reduction properties. The amount of deposited coke on used

Table 1 - List of catalysts prepared.
\begin{tabular}{lccl} 
Catalyst \# & Pt, wt.\% & Ce, wt.\% & Preparation procedure \\
\hline Cat1 & 1 & 0 & Impregnation \\
Cat2 & 1 & 1 & Coimpregnation \\
Cat3 & 1 & 5 & Coimpregnation \\
Cat4 & 1 & 1 & Sequential impregnation \\
\hline
\end{tabular}


catalysts was determined by temperature-programmed oxidation (TPO) tests. Both TPO and TPR tests were performed on a Mettler Toledo TGA/DTA851 apparatus. TPR measurements were carried out by using a $\mathrm{H}_{2}(4 \% \mathrm{v} / \mathrm{v})-\mathrm{He}$ reductive mixture with a heating rate of $5 \mathrm{~K} / \mathrm{min}$. The temperature was increased from room temperature up to $1073 \mathrm{~K}$. Prior to the TPR experiments, samples were calcined in flowing air at $773 \mathrm{~K}$ for $4 \mathrm{~h}$. In a typical TPO experiment, the catalyst sample, after $4 \mathrm{~h}$ of reaction, was cooled to room temperature, then placed into the system and heated up to $1173 \mathrm{~K}$ at a rate of $10 \mathrm{~K} / \mathrm{min}$ in $\mathrm{O}_{2}$ $(30 \% \mathrm{v} / \mathrm{v})-\mathrm{He}$ mixture with a flow rate of $50 \mathrm{~mL} / \mathrm{min}$.

The Pt and Ce metallic and oxide phases of the fresh samples, which were pretreated by calcination in flowing air at $773 \mathrm{~K}$ for $4 \mathrm{~h}$ and reduction at $773 \mathrm{~K}$ under $50 \mathrm{~mL} / \mathrm{in}_{2}$ flow for $2 \mathrm{~h}$, were analyzed by XPS. The tests were performed at the Middle East Technical University Central Laboratory using SPECS spectrometer equipped with a hemispherical electron analyzer and $\mathrm{Al}-\mathrm{K}_{\alpha} \quad\left(h=1486.56 \mathrm{eV} ; 1 \mathrm{eV}=1.6302 \times 10^{-19} \mathrm{~J}\right)$ $282 \mathrm{~W}$ dual X-ray source. The vacuum in analysis chamber was always $<1 \times 10^{-9}$ mbar. The spectra were collected at pass energy of $48 \mathrm{eV}$. The XPS data analysis was performed with the XPSPeak 4.1 program. The intensities were estimated by calculating the integral of each peak, after subtraction of the S-shaped Shirley-type background, and by fitting the curve to a combination of Lorentzian (30\%) and Gaussian (70\%) lines. All binding energies were referenced to the $C$ 1s line at $284.6 \mathrm{eV}$, which provided binding energy values with an accuracy of $\pm 0.2 \mathrm{eV}$.

SEM and EDX tests were performed using a Carl Zeiss EVO40 environmental SEM that is equipped with a $\mathrm{LaB}_{6}$ electron gun, a vacuum secondary electron (SE) detector, an elevated pressure SE detector, a backscattering electron detector (BSD) and a Bruker EDX detector. Freshly reduced catalysts were ground into fine particles and mechanically dispersed on an electrically conductive carbon film which was placed on an aluminum disc. No additional coatings or dispersive liquids were used prior to SEM and EDX measurements.

For all of the EDX elemental mapping and quantification studies, at least four different clusters of the same catalyst sample, with similar cluster sizes, were chosen for statistical comparison. Quantification values corresponding to the different clusters for a given catalyst type were typically found to be in good correlation with each other.

\subsection{Activity tests}

The catalytic reforming of methane with carbon dioxide was carried out in a fixed-bed down-flow tubular quartz reactor under atmospheric pressure. In these experiments, $100 \mathrm{mg}$ of 250-425 $\mu \mathrm{m}$ fresh catalyst particles were fixed at the center of the $4 \mathrm{~mm}$-i.d. microreactor. The temperature of the reactor oven was controlled to $\pm 0.1 \mathrm{~K}$ by a Shimaden FP-21 programmable controller. The reaction temperature was determined by a K-type sheathed thermocouple which was placed in the center of the furnace adjacent to the microreactor. The position of the catalyst bed was adjusted to remain within the constant-temperature zone $(10 \mathrm{~cm})$ of tube furnace. Position of the $1 \mathrm{~cm}$-high catalyst bed was fixed in this zone using quartz wool (Alltech).
Prior to reaction tests, the catalyst was calcined in situ in dry air ( $30 \mathrm{~mL} / \mathrm{min})$ for $4 \mathrm{~h}$ at $773 \mathrm{~K}$ and subsequently reduced in situ in $\mathrm{H}_{2}(50 \mathrm{~mL} / \mathrm{min})$ for $2 \mathrm{~h}$ at the same temperature. The reactions were performed in the temperature range of 773$973 \mathrm{~K}$ and $\mathrm{CH}_{4}: \mathrm{CO}_{2}$ ratios of $1: 1 \& 2: 1$. The volumetric flow rate was held constant at $26 \mathrm{~mL} / \mathrm{min}$, resulting in space velocity of $15,600 \mathrm{~mL} / \mathrm{h}$ g-cat. No diluents were used in the tests. The exit gases were analyzed using a gas chromatograph, Hewlett Packard HP5890, equipped with a HayeSep D column, and a thermal conductivity detector.

\section{Results}

\subsection{Characterization}

\subsubsection{Temperature programmed reduction}

Aiming to understand the differences in reduction behavior coming from preparation methodologies, TPR studies were performed on all the catalyst samples. The TPR profiles of the catalysts and the support are shown in Fig. 1. TPR profile of $\mathrm{ZrO}_{2}$ demonstrates that there is no significant weight loss up to $1073 \mathrm{~K}$ under hydrogen flow indicating no reduction of support (not shown in the figure). Bozo et al. [35] and Passos et al. [36] obtained similar results in TPR experiments for zirconia. $1 \mathrm{wt} . \% \mathrm{Pt} / \mathrm{ZrO}_{2}$ showed a steep bend around at $453 \mathrm{~K}$, which is assigned to the reduction of $\mathrm{PtO}_{2}$ phase [36,37]. At around $723 \mathrm{~K}$, one can note a gentle decrease in the curvature most probably related to the reversible adsorption of hydrogen [37,38]. All Pt$\mathrm{Ce} / \mathrm{ZrO}_{2}$ catalysts showed a weight loss at $523-573 \mathrm{~K}$ which may be attributed to both the reduction of ceria in close contact with platinum, as well as to the reduction of platinum (breakdown of Pt-O- $\mathrm{CeO}_{2}$ species created on calcinations step). The second set of mild curvatures at about $650-700 \mathrm{~K}$ is related to the surface reduction of $\mathrm{CeO}_{2}$ not in close contact with the platinum. This may be assigned to the ability of the noble metal to promote the reduction of $\mathrm{Ce}^{4+}$ via spilling of hydrogen species over the support, which has been previously mentioned in the related literature [36-39].

The weight loss for $1 \mathrm{wt} . \% \mathrm{Pt}-5 \mathrm{wt} . \% \mathrm{Ce} / \mathrm{ZrO}_{2}$ catalyst prepared by coimpregnation method (cat3) is the highest when compared with the other $1 \mathrm{wt} . \% \mathrm{Pt}-1 \mathrm{wt} . \% \mathrm{Ce} / \mathrm{ZrO}_{2}$

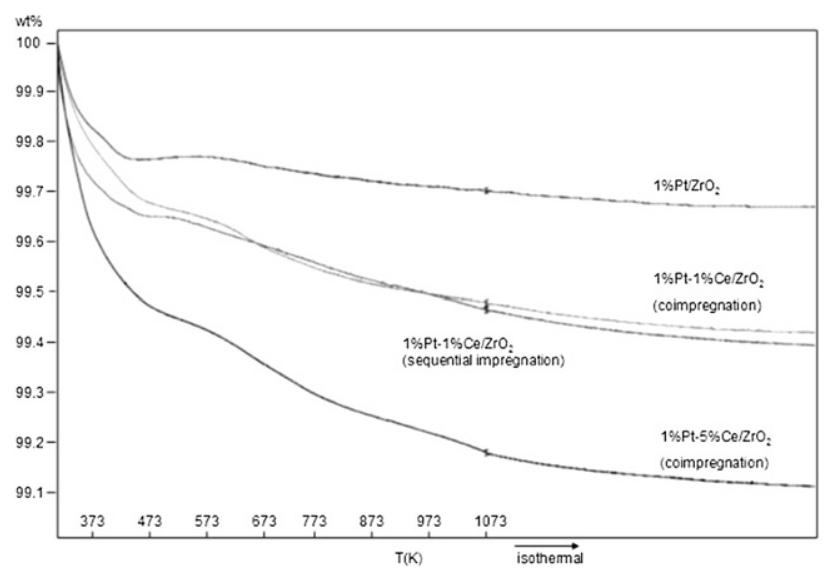

Fig. 1 - TPR profiles of $1 \% \mathrm{Pt} / \mathrm{ZrO}_{2}, 1 \% \mathrm{Pt}-1 \% \mathrm{Ce} / \mathrm{ZrO}_{2}$ (coimp.), $1 \% \mathrm{Pt}-5 \% \mathrm{Ce} / \mathrm{ZrO}_{2}$ (coimp.) and $1 \% \mathrm{Pt}-1 \% \mathrm{Ce} / \mathrm{ZrO}_{2}$ (seq. imp.). 
Table 2 - Catalyst characterization by XPS.

\begin{tabular}{|c|c|c|c|c|c|}
\hline Sample [ref.] & Preparation method & B.E. $\operatorname{Zr} 3 d_{5 / 2}(e V)$ & B.E. Pt $4 \mathrm{f}_{7 / 2}(\mathrm{eV})(\%)$ & B.E. Ce u'" (eV) & $\mathrm{Ce}^{3+}(\%)$ \\
\hline \multirow[t]{2}{*}{ Cat2 } & Coimpregnation & 182.4 & 70.8 (39) & 916.8 & 25 \\
\hline & & & $72.1(61)$ & & \\
\hline \multirow[t]{2}{*}{ Cat4 } & Sequential impregnation & 182.3 & $70.7(62)$ & 917.8 & 11 \\
\hline & & & $71.9(38)$ & & \\
\hline $\mathrm{Pt}^{\mathrm{O}}[40]$ & - & - & $71.1 \pm 0.2$ & - & - \\
\hline $\mathrm{Pt}^{2+}[40]$ & - & - & $72.2 \pm 0.2$ & - & - \\
\hline $\mathrm{Pt}^{4+}[40]$ & - & - & $74.2 \pm 0.2$ & - & - \\
\hline
\end{tabular}

catalyst prepared by either coimpregnation or sequential impregnation method, indicating that increase in Ce loading of the $\mathrm{Pt}-\mathrm{Ce} / \mathrm{ZrO}_{2}$ may improve the reducibility of the catalyst. Fig. 1 and its differential form (not given) also show that the reduction temperatures shift to lower levels as the cerium content increases, i.e. $523 \mathrm{~K}$ for cat 3 whereas $548 \mathrm{~K}$ for cat2 and $576 \mathrm{~K}$ for cat4. This result seems to be related to the increased oxygen mobility favored by the higher amount of $\mathrm{Ce}$ species that can be reduced.

In conclusion, it seems clear from the results that in Pt-Ce catalysts, the reduction treatment at $773 \mathrm{~K}$ is sufficient to produce ceria at its zero valent state $\left(\mathrm{Ce}^{4+}\right)$ and/or the creation of oxygen vacancies, and presence of $\mathrm{Ce}^{3+}$ ions and $\mathrm{Ce}^{4+} / \mathrm{Ce}^{3+}$ ratio on the samples depends on the preparation procedure of the sample prior to reduction. These results are parallel to the results presented in literature [36-39].

\subsubsection{X-ray photoelectron spectroscopy}

The extent of interaction between Pt and Ce species for the catalysts having same loads but had been prepared by different impregnation procedures was determined through analyzing the data obtained from XPS tests. For that purpose, the metallic and oxide phases of $\mathrm{Pt}$ and Ce present on 1 wt.\%Pt-1 wt.\%Ce/ $/ \mathrm{ZO}_{2}$ catalyst prepared by coimpregnation and sequential impregnation method, cat2 and cat4, respectively, were analyzed by XPS. It can be seen from Table 2 that the $\mathrm{Zr} 3 d_{5 / 2}$ binding energy remains unchanged, within the precision limits of the measurement, at around $182.3 \mathrm{eV}$, which is the typical binding energy for $\mathrm{Zr}^{4+}$, for both catalysts [39].

The main experimental $\mathrm{Pt} 4 \mathrm{f}_{7 / 2}$ peak has been deconvoluted into two components. Their binding energies and their relevant contribution to the main peak are reported in Table 2. Table 2 also includes the binding energy values of $\mathrm{Pt} 4 \mathrm{f}_{7 / 2}$ core levels of $\mathrm{Pt}^{0}, \mathrm{Pt}^{2+}$ and $\mathrm{Pt}^{4+}$, which were reported in the related literature as reference bases [40]. In the XPS profiles of cat4, the peak at $71.9 \mathrm{eV}$ indicates the presence of $\mathrm{Pt}^{2+}$ species, and the one centered at $70.7 \mathrm{eV}$ corresponds to $\mathrm{Pt}^{0}$ species. For cat2, there appeared to be a small electropositive shift in $\mathrm{Pt} 4 \mathrm{f}_{7 / 2}$ peak binding energies measured relative to cat 4 suggesting that $\mathrm{Pt}$ may have been slightly more oxidized in this sample. Serre et al. [41] mentioned that a slight increase in Pt oxidation state may reflect charge transfer from metal to ceria, indicating that Ce is slightly reduced. This shift corresponds to a net electron transfer from $\mathrm{Pt}$ to Ce due to the existence of strong and extensive $\mathrm{Pt}-\mathrm{Ce}$ interaction between both $\mathrm{Pt}$ and Ce precursors during coimpregnation on the $\mathrm{ZrO}_{2}$ surface and between Pt and Ce species during subsequent high temperature thermal treatments, i.e. calcination and reduction, at $773 \mathrm{~K}$.
Figs. 2 and 3 show the Ce 3d XP spectra obtained with $1 \mathrm{wt} . \% \mathrm{Pt}-1 \mathrm{wt} . \% \mathrm{Ce} / \mathrm{ZrO}_{2}$ catalysts prepared by both coimpregnation and sequential impregnation method (cat2 and cat4), respectively, both after reduction at $773 \mathrm{~K}$. The electronic structure of $\mathrm{CeO}_{2}$ has been a matter of controversy. The first really well-resolved spectra were published by Burroughs et al. in 1976 [42]. The complexity of Ce spectra is caused by strong hybridization between the Ce $4 \mathrm{f}$ levels and the $\mathrm{O} 2 \mathrm{p}$ states [43]. According to the literature [43-45], the complex spectrum of Ce $3 \mathrm{~d}$ can be resolved into 10 components, which can be obtained curve-fitting analysis (v's represent the Ce $3 d_{5 / 2}$ contribution and $u$ 's represent the Ce $3 d_{3 / 2}$ contribution) as shown in Figs. 4 and 5 . The peaks labeled $v, v^{\prime \prime}$ and $v^{\prime \prime \prime}$ can be attributed to $\mathrm{Ce}^{4+} ; v$ and $v^{\prime \prime}$ are due to a mixture of Ce $3 \mathrm{~d}^{9} 4 \mathrm{f}^{2} \mathrm{O}$ $2 \mathrm{p}^{4}$ and $\mathrm{Ce} 3 \mathrm{~d}^{9} 4 \mathrm{f}^{1} \mathrm{O} 2 \mathrm{p}^{5}$ configurations while $\mathrm{v}^{\prime \prime}$ corresponds to a pure $\mathrm{Ce} 3 \mathrm{~d}^{9} 4 \mathrm{f}^{0} \mathrm{O} 2 \mathrm{p}^{6}$ final state. On the other hand, $v_{0}$ and $v^{\prime}$ are assigned to the Ce $3 d^{9} 4 f^{2} O 2 p^{5}$ and Ce $3 d^{9} 4 f^{1} O 2 p^{6}$ configurations of $\mathrm{Ce}^{3+}$; $u$ structures, due to the $\mathrm{Ce} 3 \mathrm{~d}_{3 / 2}$ can be explained in the same way (Table 3).

In literature, two different approaches have been followed to evaluate the degree of ceria reduction from XPS. Some authors have used percentage of area of the $u^{\prime \prime \prime}$ peak in total Ce $3 \mathrm{~d}$ region to describe the total amount of $\mathrm{Ce}^{4+}$ in the sample $[46,47]$. However, this approach leads to erroneous quantitative results [48]. The second approach considers the relative integrated peak areas corresponding to the $u_{0}\left(v_{0}\right)$ and $u^{\prime}\left(u^{\prime}\right)$ peaks as representatives of $\mathrm{Ce}^{3+}$, in total Ce $3 d$ band $[44,45,49]$. In this way, after deconvolution of the experimental spectra, the degree of Ce reduction can be calculated from the ratio between the sum of the integrated peak areas of $u_{0}, u^{\prime}, v_{0}$

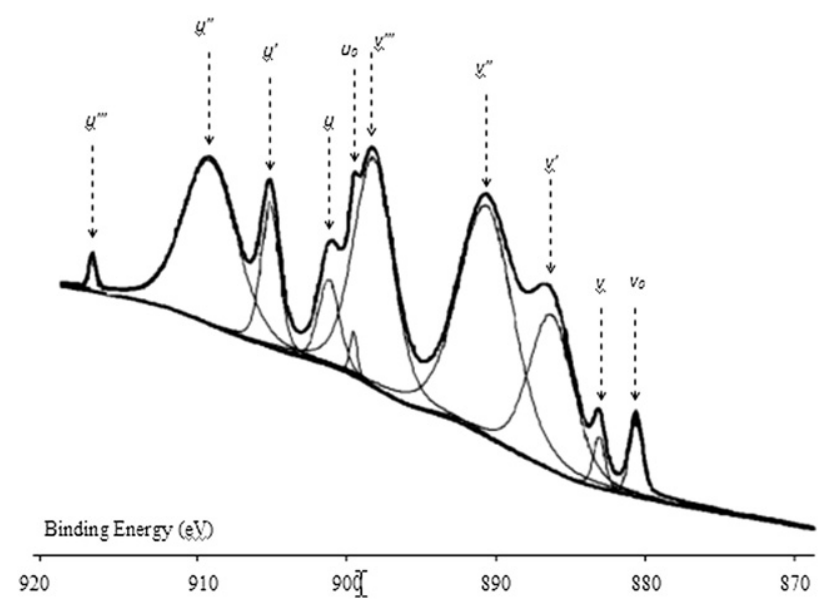

Fig. 2 - Ce $3 \mathrm{~d}$ XPS spectra of $1 \% \mathrm{Pt}-1 \% \mathrm{Ce} / \mathrm{ZrO}_{2}$ prepared by coimpregnation (cat2). 


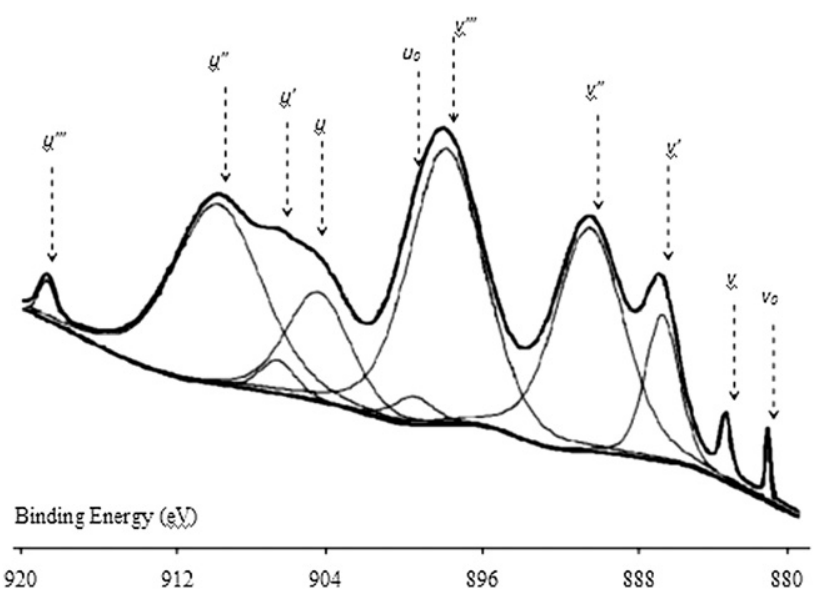

Fig. 3 - Ce $3 \mathrm{~d}$ XPS spectra of $1 \% \mathrm{Pt}-1 \% \mathrm{Ce} / \mathrm{ZrO}_{2}$ catalyst prepared by sequential impregnation (cat4).

and $v^{\prime}$ peaks and the sum of the integrated peak areas of all the peaks [Eq. (6)]

$\mathrm{Ce}^{3+}(\%)=\frac{100 \cdot\left[S\left(u_{0}\right)+S\left(u^{\prime}\right)+S\left(v_{0}\right)+S\left(v^{\prime}\right)\right]}{\sum[S(u)+S(v)]}$

Data in Table 2 show that the amount of $\mathrm{Ce}^{3+}$ estimated from the above equation was $25 \%$ for cat2, whereas $11 \%$ for cat 4 . Coimpregnation of Pt and Ce onto $\mathrm{ZrO}_{2}$ support and subsequent thermal treatments has resulted in an increase in the amount of $\mathrm{Ce}^{3+}$ state. It must also be recalled that, as initially reported by Paparazzo [50], $\mathrm{CeO}_{2}$ can suffer spontaneous reduction at room temperature during XPS measurements by action of the X-ray irradiation combined with the ultra-highvacuum environment. Considering that the same support has been used for the preparation of both Pt-Ce catalysts, and that the XPS analysis has been carried out under the same conditions for both samples, it can be assumed that $\mathrm{Ce}^{4+}$ photo reduction by X-ray irradiation is similar for both catalysts, and, as a consequence, differences in reducibility are only originated from impregnation strategy. On the other hand, the binding energies of the Ce $u^{\prime \prime \prime}$ peak are also reported in Table 2 . The value is $916.8 \mathrm{eV}$ for cat2 whereas $917.8 \mathrm{eV}$ for cat 4, indicating and validating that Ce in cat4, 1 wt.\%Pt-1 wt.\%Ce/ $/ \mathrm{ZrO}_{2}$ catalyst prepared by sequential impregnation, is in higher oxidized state.

XPS data indicate that the increase in Pt oxidation state and the higher amount of reduced Ce in cat 2 is a result of net electron transfer from Pt to Ce led by the strong and extensive Pt-Ce interaction during coimpregnation - between their precursors - and during subsequent high temperature thermal treatments (calcination and reduction at $773 \mathrm{~K}$ ).

\subsubsection{Scanning electron microscopy and energy dispersive $\mathrm{X}$-ray analysis}

Freshly reduced Pt-Ce catalysts (cat2 and cat4) were tested using SEM-EDX to obtain information on their microstructural and metal dispersion properties. Metal mapping studies were
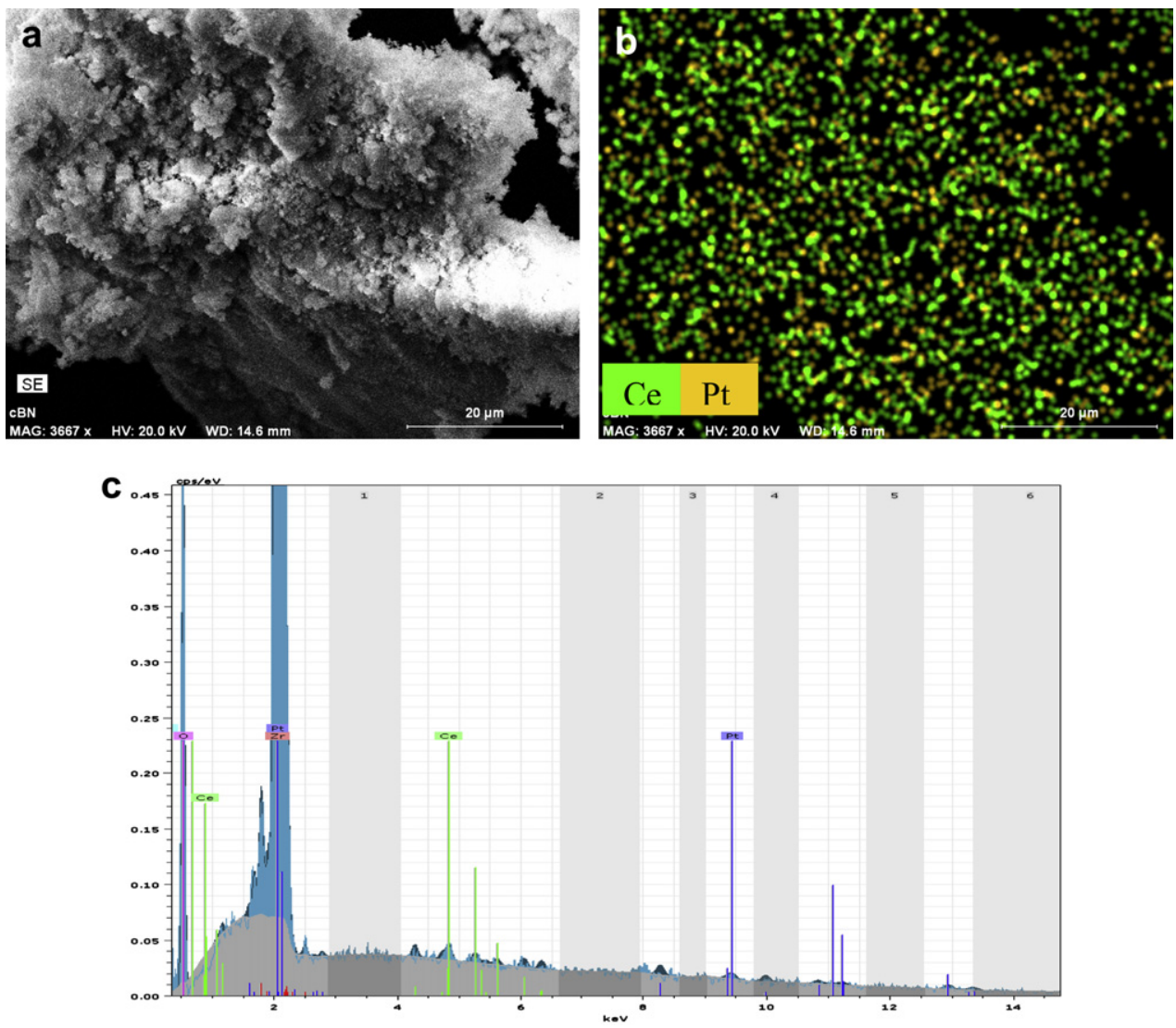

Fig. 4 - 1\%Pt-1\%Ce/ZrO 2 catalyst prepared by coimpregnation (cat2): (a) SEM bright area image, (b) Pt + Ce mapping, and (c) EDX spectrum. 

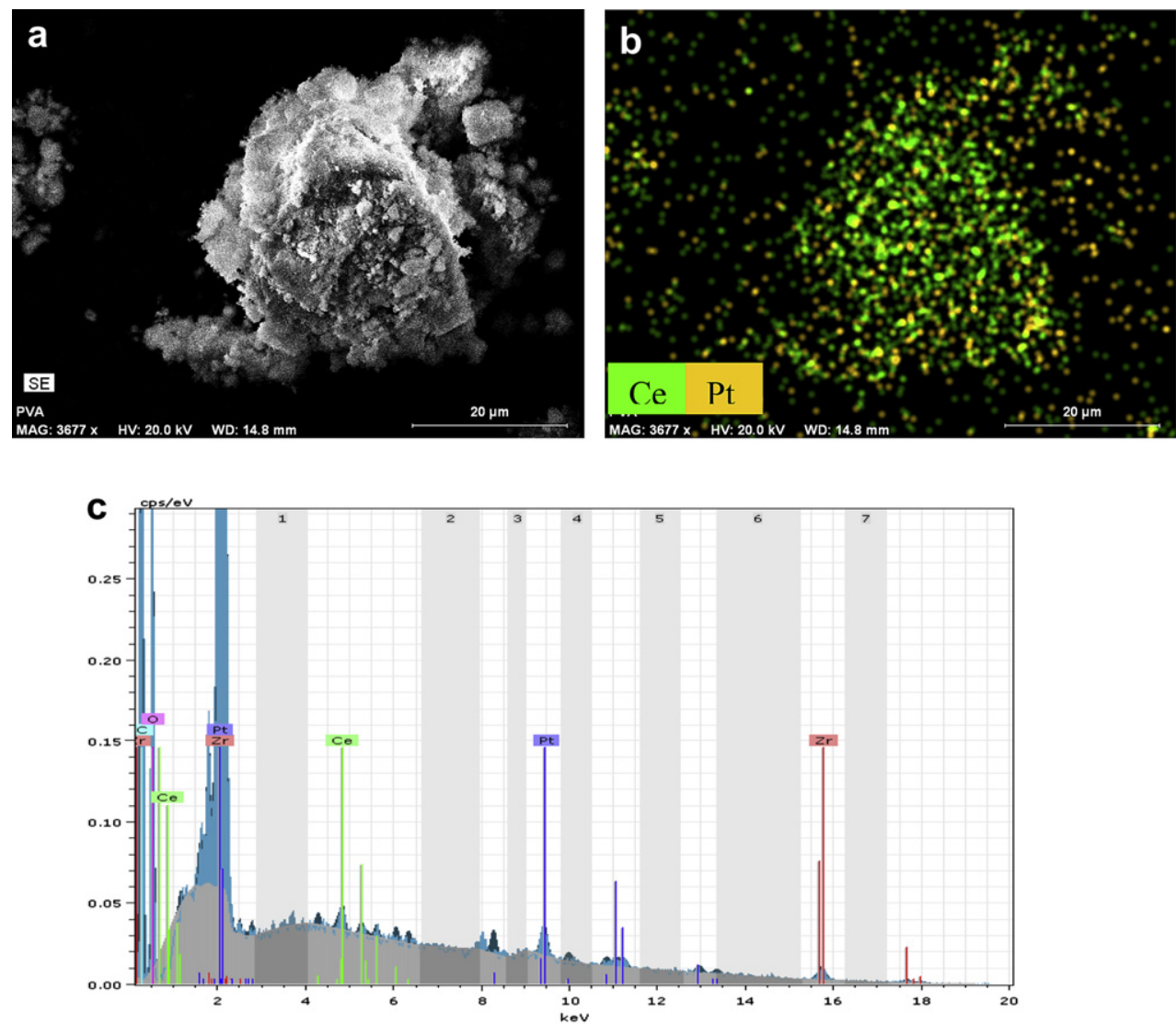

Fig. 5 - 1\%Pt-1\%Ce/ZrO ${ }_{2}$ catalyst prepared by seq. impregnation (cat4): (a) SEM bright area image, (b) Pt $+\mathrm{Ce}$ mapping, and (c) EDX spectrum.

used to understand the dispersion of metals and their agglomeration behaviors on the support surface; the $\mathrm{Pt}+\mathrm{Ce}$ metal mappings obtained for different samples are given in Figs. 4 and 5. For each sample, a representative set of results, including a bright area image, the EDX profile and the $\mathrm{Pt}+\mathrm{Ce}$ mapping, are given.

In particular; Pt is observed to be well and homogeneously dispersed over the surface of $1 \mathrm{wt} . \% \mathrm{Pt}-1 \mathrm{wt} . \% \mathrm{Ce} / \mathrm{ZrO}_{2}$ catalyst prepared by coimpregnation (cat2). The low signal of Pt from the EDX spectrum can be attributed to the high dispersion and small particle size of Pt metal on the surface. It is also detected that Pt signal is always proportional to the Ce signal, which may probably result from the presence of Pt particles which are located over or in the close proximity of Ce sites.

However; over the surface of $1 \mathrm{wt} . \% \mathrm{Pt}-1 \mathrm{wt} . \% \mathrm{Ce} / \mathrm{ZrO}_{2}$ catalyst prepared by sequential impregnation (cat 4), Pt signal in EDX spectrum is significantly higher than that of the

Table 3 - Ce $3 d_{5 / 2}$ configuration.

\begin{tabular}{|c|c|}
\hline Peaks & Configurations \\
\hline$v_{0}$ & Ce $3 d^{9} 4 f^{2} O 2 p^{5}$ configurations of $\mathrm{Ce}^{3+}$ \\
\hline$v \& v^{\prime \prime}$ & Mixture of Ce $3 d^{9} 4 f^{2} O 2 p^{4}$ and Ce $3 d^{9} 4 f^{1} O 2 p^{5}$ \\
\hline$v^{\prime}$ & Ce $3 d^{9} 4 f^{1} O 2 p^{6}$ configurations of $\mathrm{Ce}^{3+}$ \\
\hline$v^{\prime \prime \prime}$ & Pure Ce $3 d^{9} 4 f^{0}$ O $2 p^{6}$ final state \\
\hline
\end{tabular}

coimpregnated sample (cat2). This shows us that Pt dispersion is low compared to the sample prepared by coimpregnation method and Pt is in the form of agglomerates.

The weight percentages of the Ce and Pt species over the surface of cat 2 and cat 4 were determined by EDX; the Ce and Pt weight percentages are 2.32 and 5.08, respectively, for cat2, whereas are 1.37 and 6.86 , respectively, for cat4.

\subsubsection{Temperature programmed oxidation}

TGA tests were conducted over used catalysts, namely, cat2, cat 3 and cat 4 in order to determine the amount of carbon formation after $4 \mathrm{~h}$ of time on stream reaction tests at $973 \mathrm{~K}$ for the reaction with the feed having $\mathrm{CH}_{4}: \mathrm{CO}_{2}$ ratio of $1: 1$. During the TPO analyses (Fig. 6), the weights of $1 \mathrm{wt} . \% \mathrm{Pt}-$ $1 \mathrm{wt} . \% \mathrm{Ce} / \mathrm{ZrO}_{2}$ and $1 \mathrm{wt} . \% \mathrm{Pt}-5 \mathrm{wt} . \% \mathrm{Ce} / \mathrm{ZrO}_{2}$ catalysts prepared by coimpregnation method (cat2 and cat3) showed very small change with the temperature increase, which is the indication of little coke formation during the reaction. On the other hand, TGA experiments showed a weight loss of $7 \%$ on treating the $1 \mathrm{wt} . \% \mathrm{Pt}-1 \mathrm{wt} . \% \mathrm{Ce} / \mathrm{ZrO}_{2}$ catalyst prepared by sequential impregnation method (cat4), indicating a significant amount of carbon deposition during the course of $4 \mathrm{~h}$ onstream reaction. The overall weight loss would correspond to the sum of change due to oxidation of carbonaceous species and oxidation of reduced cerium and platinum [32].

The TGA tests were also conducted on the used catalysts (cat2 and cat3) in the reaction tests with a higher $\mathrm{CH}_{4}: \mathrm{CO}_{2}$ ratio 


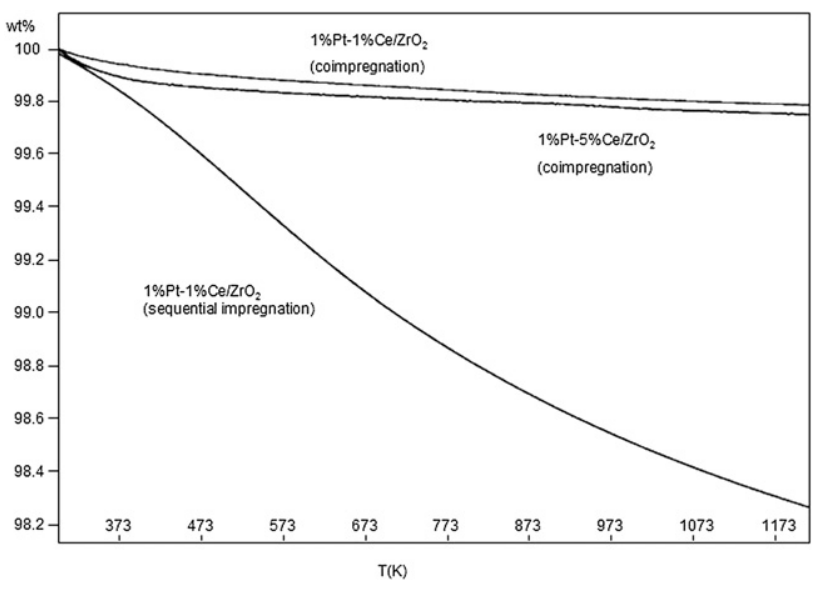

Fig. 6 - Temperature programmed oxidation (TPO) profiles of spent catalysts after $4 \mathrm{~h}$ of time on stream reaction tests at $973 \mathrm{~K}$ with $\mathrm{CH}_{4} / \mathrm{CO}_{2}=1 / 1: 1 \% \mathrm{Pt}-1 \% \mathrm{Ce} / \mathrm{ZrO}_{2}$ (coimp.), $1 \% \mathrm{Pt}-5 \% \mathrm{Ce} / \mathrm{ZrO}_{2}$ (coimp.) and $1 \% \mathrm{Pt}-1 \% \mathrm{Ce} / \mathrm{ZrO}_{2}$ (seq. imp.).

of 2:1 to determine the amount of carbon formation after $4 \mathrm{~h}$ of reaction at $973 \mathrm{~K}$ (Fig. 7). The profiles indicate that carbon formation is not significant even under severe conditions. Additionally, higher Ce load limits carbon deposition.

\subsection{Carbon dioxide reforming of methane}

In the current work, a parametric study on $\mathrm{Pt}-\mathrm{Ce} / \mathrm{ZrO}_{2}$ system for DR reaction, which considers the effects of reaction temperature, feed composition (i.e. $\mathrm{CH}_{4} / \mathrm{CO}_{2}$ ratio in the feed), reaction time and catalyst preparation method as the parameters, was conducted.

\subsubsection{Effect of reaction temperature}

The catalysts were tested in $\mathrm{CO}_{2}$ reforming of methane at 773$973 \mathrm{~K}$ with $\mathrm{CH}_{4}: \mathrm{CO}_{2}$ ratio of $1: 1$. Fig. $8 \mathrm{a}-\mathrm{C}$ shows the $\mathrm{CH}_{4}$ conversion (a), $\mathrm{CO}_{2}$ conversion (b) and $\mathrm{H}_{2}$ /CO molar ratio (c) as a function of reaction temperature. Activity trends reveal that

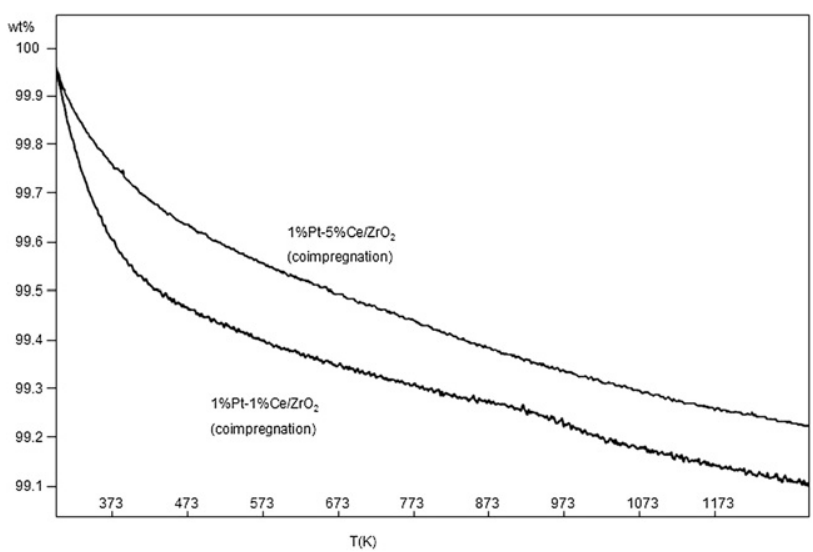

Fig. 7 - Temperature programmed oxidation (TPO) profiles of spent catalysts after $4 \mathrm{~h}$ of time on stream reaction tests at $973 \mathrm{~K}$ with $\mathrm{CH}_{4} / \mathrm{CO}_{2}=2 / 1: 1 \% \mathrm{Pt}-1 \% \mathrm{Ce} / \mathrm{ZrO}_{2}$ (coimp.) and $1 \% \mathrm{Pt}-5 \% \mathrm{Ce} / \mathrm{ZrO}_{2}$ (coimp.).
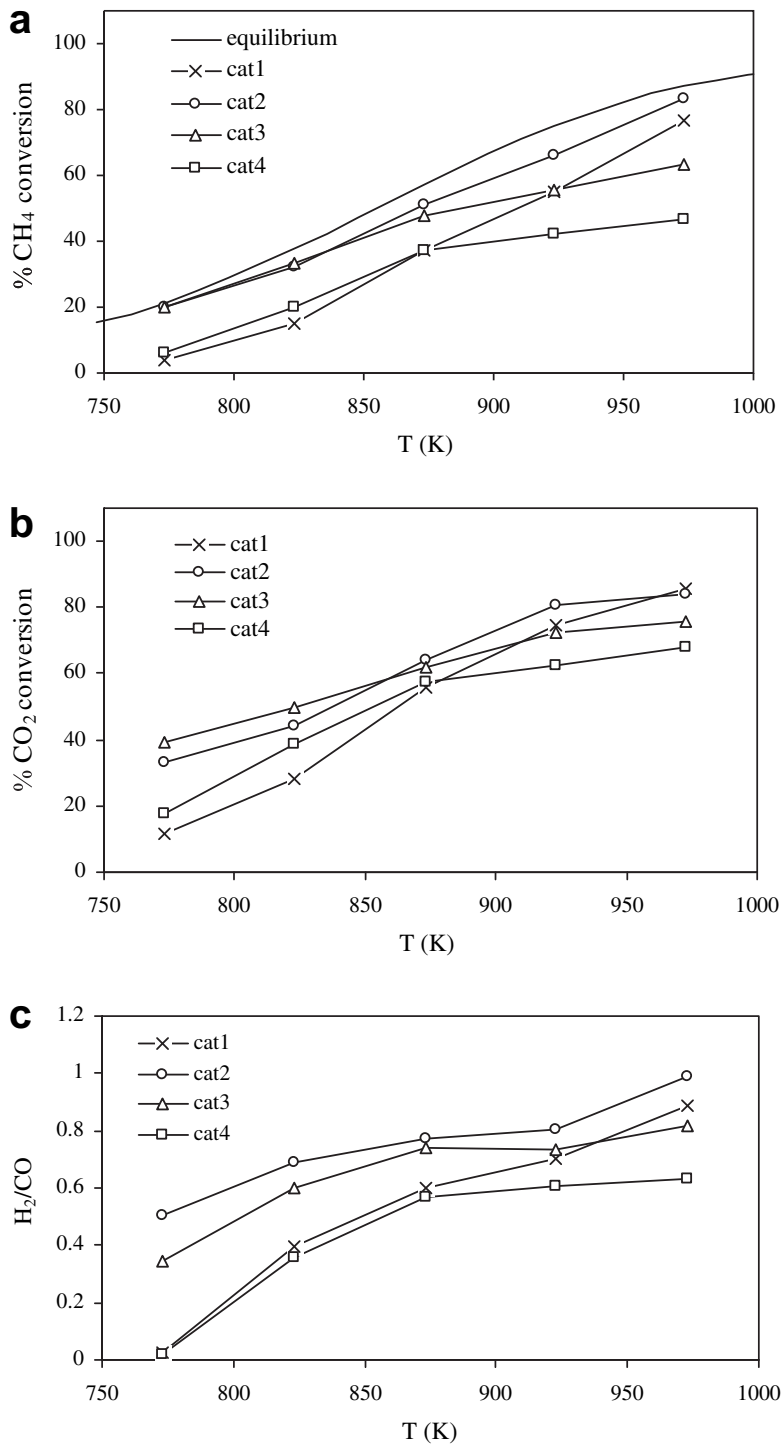

Fig. $8-\mathrm{CH}_{4}$ conversion (a), $\mathrm{CO}_{2}$ conversion (b) and $\mathrm{H}_{2} / \mathrm{CO}$ molar ratio (c) for different catalysts in the DR of methane as a function of the reaction temperature. Values measured at the end of $4 \mathrm{~h}$ on stream. $\mathrm{CH}_{4} / \mathrm{CO}_{2}=1 / 1$. Space velocity $=15,600 \mathrm{~mL} / \mathrm{h}$ g-cat.

$\mathrm{CH}_{4}$ and $\mathrm{CO}_{2}$ conversions increase with the temperature for each catalyst. The different activity levels of the catalysts clearly show the effects of impregnation strategy and Ce loading on activity and selectivity. $\mathrm{CH}_{4}$ conversions over $1 \mathrm{wt} . \% \mathrm{Pt}-1 \mathrm{wt} . \% \mathrm{Ce} / \mathrm{ZrO}_{2}$ (cat2) and $1 \mathrm{wt} . \% \mathrm{Pt}-5 \mathrm{wt} . \% \mathrm{Ce} / \mathrm{ZrO}_{2}$ (cat3) prepared by coimpregnation method are close at lower temperatures, whereas at higher temperatures, the catalyst with 5 wt.\% Ce loading shows an inferior activity profile. High $\mathrm{CH}_{4}$ conversions, almost equal to the thermodynamic level, were obtained on $1 \mathrm{wt} . \% \mathrm{Pt}-1 \mathrm{wt} . \% \mathrm{Ce} / \mathrm{ZrO}_{2}$ catalyst prepared by coimpregnation method (cat2) over the whole temperature range investigated: the $\mathrm{CH}_{4}$ conversion ranged from $20.1 \%$ at $773 \mathrm{~K}$ to $83.6 \%$ at $973 \mathrm{~K}$, which correspond to $95.7 \%$ and $96.1 \%$ of the thermodynamically maximum attainable conversion levels, respectively. 
It is clear that the introduction of small amount of cerium (1 wt.\%) to $\mathrm{Pt} / \mathrm{ZrO}_{2}$ via coimpregnation method led to an increase in the activity. It is also noteworthy from Fig. 6a-c that addition of $1 \mathrm{wt} . \% \mathrm{Ce}$ to the $\mathrm{Pt} / \mathrm{ZrO}_{2}$ catalyst via coimpregnation method led to a superior catalytic performance, while the $1 \mathrm{wt} . \% \mathrm{Pt}-1 \mathrm{wt} . \% \mathrm{Ce} / \mathrm{ZrO}_{2}$ catalyst prepared by sequential impregnation (cat4) displayed the lowest $\mathrm{CH}_{4}$ and $\mathrm{CO}_{2}$ conversions as well as the lowest $\mathrm{H}_{2} / \mathrm{CO}$ molar ratios over the whole temperature range. On the other hand; increasing the loading of Ce from 1 to $5 \mathrm{wt}$.\% resulted in a decrease in the activity of the catalyst at high temperatures.

Additionally, although $\mathrm{CH}_{4}$ and $\mathrm{CO}_{2}$ were present in the feed in a 1:1 ratio, $\mathrm{CO}_{2}$ conversion levels have always been found to be higher than the $\mathrm{CH}_{4}$ conversions, which is due to the reverse water-gas shift (RWGS) reaction occurring simultaneously with DR $[4,15]$ :

$\mathrm{CO}_{2}+\mathrm{H}_{2}=\mathrm{CO}+\mathrm{H}_{2} \mathrm{O}, \Delta \mathrm{H}_{298}^{0}=+41 \mathrm{~kJ} \mathrm{~mol}^{-1}$

RWGS consumes part of the $\mathrm{H}_{2}$ produced by DR; this fact supports the observation that the $\mathrm{H}_{2} / \mathrm{CO}$ ratio always attains values lower than unity, but tends to 1 at higher temperatures due to dominated DR activity, as shown in Fig. 6c. The comparison of $\mathrm{CO}_{2}$ and $\mathrm{CH}_{4}$ conversion levels of catalyst clearly shows that the RWGS reaction activity is suppressed when 1 wt.\%Pt-1 wt.\%Ce/ $\mathrm{ZrO}_{2}$ coimpregnated catalyst (cat2) was used.

\subsubsection{Effect of time-on-stream (TOS) activity testing}

TOS activity tests were performed at $973 \mathrm{~K}$ at fixed velocity with $\mathrm{CH}_{4}: \mathrm{CO}_{2}$ ratio of $1: 1$ in the feed (where the highest conversions were obtained) for all four samples for $4 \mathrm{~h}$ of TOS. Fig. 9a-c shows the $\mathrm{CH}_{4}$ conversion (a), $\mathrm{CO}_{2}$ conversion (b) and the $\mathrm{H}_{2} / \mathrm{CO}$ molar ratio (c) in the product stream, respectively, as a function of the reaction time. At the end of 4 th hour of TOS, the unpromoted $\mathrm{Pt} / \mathrm{ZrO}_{2}$ catalyst lost $5.5 \%$ of its initial $\mathrm{CH}_{4}$ activity whereas both the Ce-promoted catalysts prepared by coimpregnation method (cat2 and cat3) only lost $4 \%$ of their $\mathrm{CH}_{4}$ activity. This shows the beneficial effect of $\mathrm{Ce}$ addition on the overall stability. For the $1 \mathrm{wt}$.\%Ce-doped Pt/ $\mathrm{ZrO}_{2}$, the increase in the dissociation ability and subsequent cleaning capacity results in a catalyst with enhanced activity and stability for the $\mathrm{CO}_{2}$ reforming reaction. However, increasing the Ce loading from $1 \mathrm{wt}$ \% to $5 \mathrm{wt}$ \% did not have a significant improvement on the stability.

The 1 wt.\%Pt-1 wt.\%Ce/ $/ \mathrm{rO}_{2}$ catalyst prepared by sequential impregnation (cat4) showed lower activity compared to other samples and exhibited highly linear deactivation during the first $30 \mathrm{~min}$ on-stream, due to the fast deposition of the inactive carbon, as observed in TPO experiments. The $\mathrm{CH}_{4}$ activity leveled off to stable values with about $22 \%$ loss at the end of $4 \mathrm{~h}$. In addition, cat 4 is the only catalyst sample over which the $\mathrm{CO}_{2}$ conversion decreased continuously by almost 9\% during the reaction period; for all other catalysts the $\mathrm{CO}_{2}$ conversion was constant about $85 \%$ over the $4 \mathrm{~h}$ of reaction. Moreover, $1 \mathrm{wt} . \% \mathrm{Pt}-1 \mathrm{wt} . \% \mathrm{Ce} / \mathrm{ZrO}_{2}$ catalyst prepared by coimpregnation method exhibited tremendous stability under reaction conditions where carbon deposition is thermodynamically favorable, indicating the advantageous effect of the coimpregnation method on the stability of the catalysts.
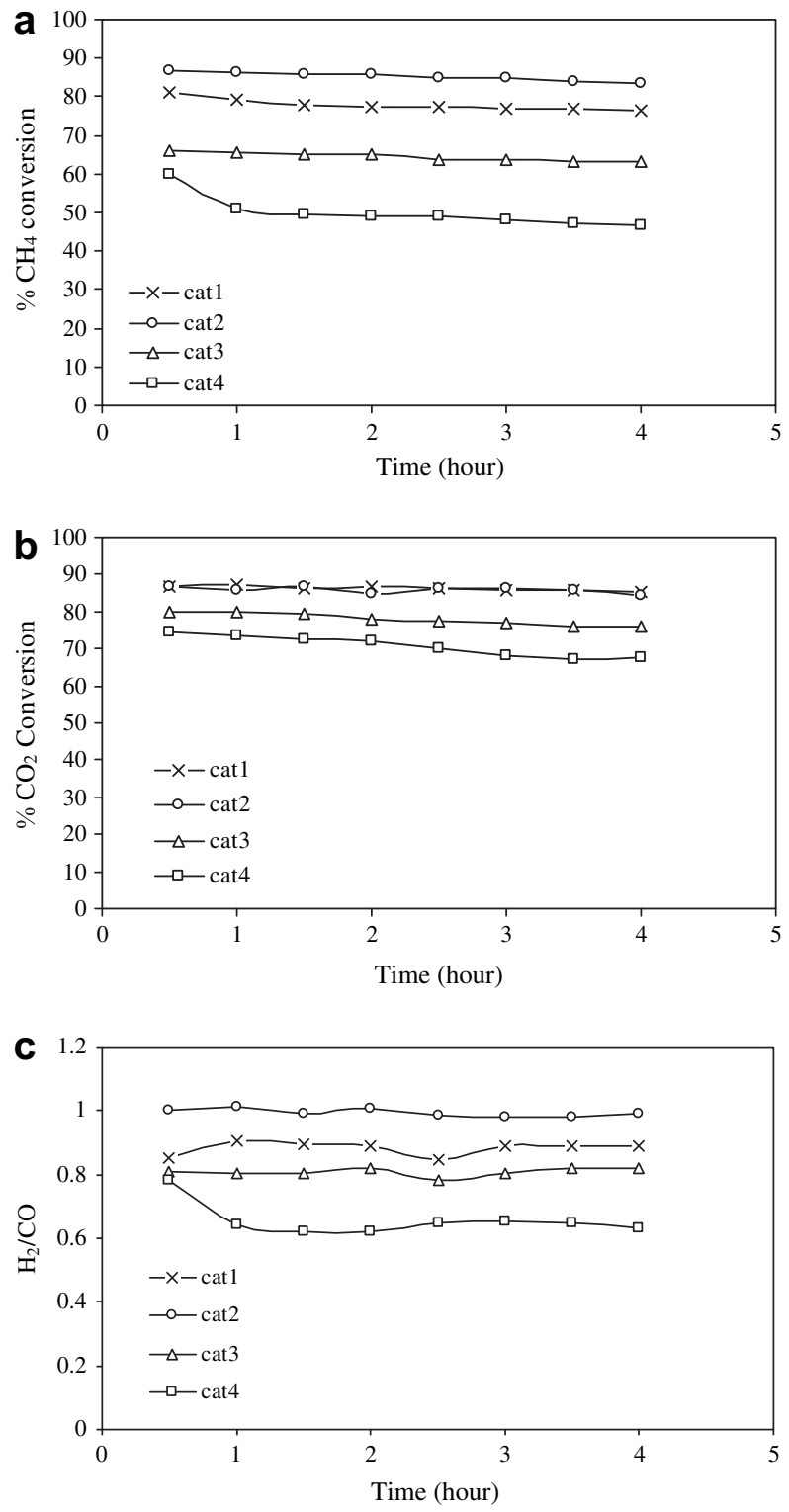

Fig. $9-\mathrm{CH}_{4}$ conversion (a), $\mathrm{CO}_{2}$ conversion (b) and $\mathrm{H}_{2} / \mathrm{CO}$ molar ratio (c) for different catalysts in the DR of methane as a function of reaction time. Reaction temperature $=973 \mathrm{~K} . \mathrm{CH}_{4} / \mathrm{CO}_{2}=1 / 1$. Space velocity $=15,600 \mathrm{~mL} / \mathrm{h} \mathrm{g}$-cat.

\subsubsection{Effect of $\mathrm{CH}_{4} / \mathrm{CO}_{2}$ ratio in the feed}

A high $\mathrm{CH}_{4} / \mathrm{CO}_{2}$ feed ratio $(>1.0)$ is considered as a severe condition for $\mathrm{CO}_{2}$ reforming of methane. The stoichiometry of $\mathrm{DR}$ reaction is 1 to 1 for $\mathrm{CO}_{2}$ and $\mathrm{CH}_{4}$. When the ratio is greater than 1.0, methane becomes excess and the carbon formed upon its decomposition on Pt may not find enough mobile oxygen to be cleaned out; the produced carbon, via the methane decomposition reaction [Eq. (4)], will deposit on the surface of the catalyst, and result in deactivation of the catalyst [51].

Aiming to understand the performance characteristics, i.e. activity and selectivity, of the catalysts at higher $\mathrm{CH}_{4} / \mathrm{CO}_{2}$ feed ratios, $\mathrm{CH}_{4}: \mathrm{CO}_{2}$ ratio was increased to $2: 1$ at $973 \mathrm{~K}$ (Figs. 10, 11). 


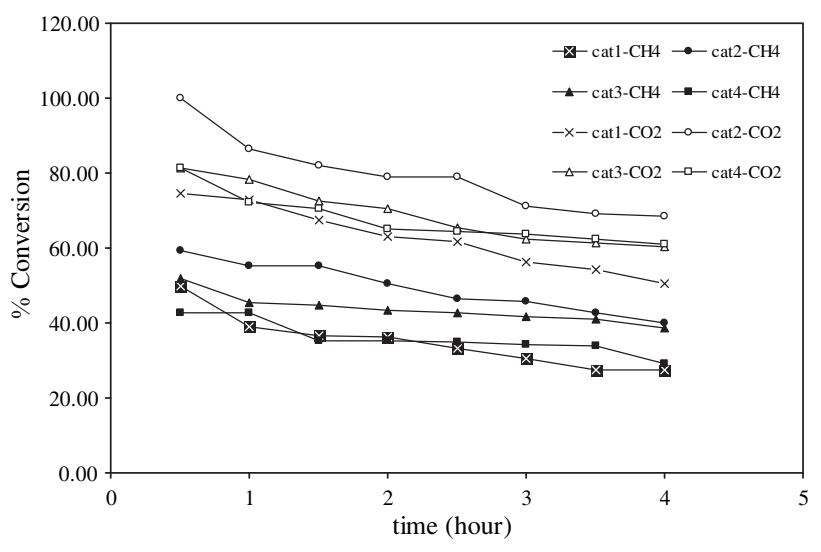

Fig. $10-\mathrm{CH}_{4} \& \mathrm{CO}_{2}$ conversions for the different catalysts in the DR of methane as a function of reaction time. Reaction temperature $=973 \mathrm{~K} . \mathrm{CH}_{4} / \mathrm{CO}_{2}=2 / 1$. Space velocity $=15,600 \mathrm{~mL} / \mathrm{h}$ g-cat.

Under these severe conditions, both reactants for each catalyst demonstrated activity rates in different extents throughout the whole time-on stream test. At the very beginning of the reaction $(t=30 \mathrm{~min})$, the conversion of $\mathrm{CH}_{4}$ and $\mathrm{CO}_{2}$ for 1 wt.\%Pt-1 wt.\%Ce/ $\mathrm{ZrO}_{2}$ catalyst prepared by coimpregnation method (cat2) was $59 \%$ and $100 \%$, respectively, whereas at the end of the $4 \mathrm{~h}$, the conversions decreased down to $40 \%$ and $68 \%$, correspondingly. However, it is seen that the activities of the samples with $5 \%$ Ce loading (cat3) leveled off to stable values, which is about $40 \% \mathrm{CH}_{4}$ conversion, with approximately $10 \%$ loss of $\mathrm{CH}_{4}$ activity at the end of $4 \mathrm{~h}$ of reaction. Unlike the results at $\mathrm{CH}_{4} / \mathrm{CO}_{2}=1.0$, it is observed that $1 \mathrm{wt} . \% \mathrm{Pt}-5 \mathrm{wt} . \% \mathrm{Ce} / \mathrm{ZrO}_{2}$ catalyst prepared by coimpregnation method (cat3) displayed the most favorable stability profile due to its relatively low conversion level at the beginning of the reaction. It should be noted that $90-95 \%$ of the activity loss was observed till the end of $3 \mathrm{~h}$ TOS and then the activity has reached stable levels. Addition of higher amount of ceria

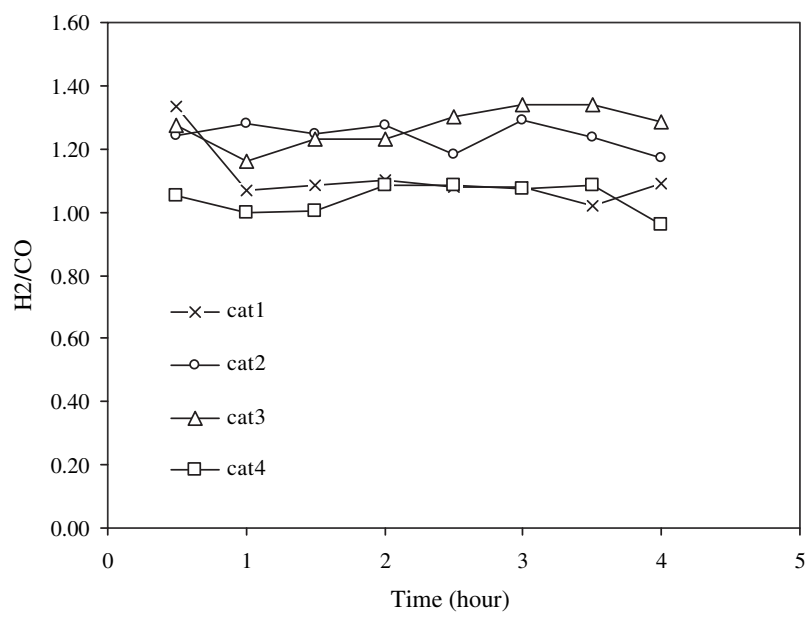

Fig. $11-\mathrm{H}_{2} / \mathrm{CO}$ molar ratio values for the different catalysts in the DR product stream as a function of reaction time. Reaction temperature $=973 \mathrm{~K} . \mathrm{CH}_{4} / \mathrm{CO}_{2}=2 / 1$. Space velocity $=15,600 \mathrm{~mL} / \mathrm{h}$ g-cat. resulted in an increase in the oxygen storage capacity of the support, as has been shown for different $\mathrm{CeO}_{2}$-containing systems [31].

Moreover, for each catalyst, $\mathrm{H}_{2} / \mathrm{CO}$ ratio ranged between 1.00 and 1.35, which is higher than the stoichiometric ratio of 1.0 and may have resulted from the decomposition of excessive $\mathrm{CH}_{4}$; the higher the amount of supplied $\mathrm{CH}_{4}$, the greater both the concentration of deposited carbonaceous species formed by $\mathrm{CH}_{4}$ decomposition [Eq. (3)] and the amount of hydrogen at the expense of stability.

\section{Discussion}

In this work; DR of methane has been studied over $\mathrm{Pt} / \mathrm{ZrO}_{2}$ catalysts promoted with Ce using different impregnation strategies and cerium amounts. Use of cerium was found to be potentially beneficial for $\mathrm{CO}_{2}$ reforming of methane activity of $\mathrm{Pt} / \mathrm{ZrO}_{2}$. The XPS results given in Table 2, showing the changes in oxidation states of both Pt and Ce on catalysts prepared by different methods, and the results of the performance tests (Figs. 8,9 ) indicate that addition of cerium improved the amount of surface oxygen through reduction/oxidation cycle of $\mathrm{CeO}_{x}$ and the reducibility of the oxide support; this combined effect enhances the long-term activity and stability of the catalyst. The improved surface oxygen transfer ability upon $\mathrm{Ce}$ addition is mentioned in the literature [31,33]. The effects of the Ce on catalyst activity depended on the cerium loading used and impregnation strategy.

Addition of $1 \mathrm{wt}$ \% $\mathrm{Ce}$ to the $\mathrm{Pt} / \mathrm{ZrO}_{2}$ catalyst via coimpregnation method led to superior catalytic activities and stabilities, which may be related both to the increased dispersion of the Pt in low-loaded Ce samples, as mentioned in literature for alumina supported catalysts [51], and coke gasification by ceria, since such addition of ceria results in an increase in the oxygen transfer ability of the support $[31,33]$. It was claimed in the previous studies $[5,19,20,22]$ that during DR on $\mathrm{Pt} / \mathrm{ZrO}_{2}$, (i) $\mathrm{CH}_{4}$ decomposes on Pt forming carbon and hydrogen, (ii) hydrogen partially reduces the support in the metal periphery, (iii) $\mathrm{CO}_{2}$ dissociates on $\mathrm{ZrO}_{2}$ support near the metal particle forming $\mathrm{CO}$ and oxygen, (iv) oxygen formed on support is transferred to Pt and cleans it from coke and (v) the dissociated oxygen reoxidizes the support. As can be easily understood, if oxygen transfer rate from the support to the metal is less than the carbon formation rate on $\mathrm{Pt}$, catalyst deactivates. In our case for cat2, in addition to $\mathrm{O}$ directly supplied to Pt from $\mathrm{ZrO}_{2}$, the presence of $\mathrm{Ce}^{3+}$ on the surface creates an additional storage capacity for oxygen coming from $\mathrm{ZrO}_{2}$ support; $\mathrm{CeO}_{x}$ goes through continuous reduction/ oxidation cycle during the reaction producing mobile surface oxygen, and enhances the oxygen transfer to Pt, which makes the metal and catalysts more resistant to carbon deposition.

The 1 wt.\%Pt-1 wt.\% Ce/ $\mathrm{ZrO}_{2}$ catalyst prepared by sequential impregnation (cat4) showed the lowest activity and stability profiles whereas same catalysts prepared by coimpregnation method (cat 2) displayed superior catalytic performance both in terms of activity and stability. Throughout sequential impregnation process, impregnation of $\mathrm{Ce}$ precursor onto the support was followed by high temperature heat treatment in a muffle furnace at $773 \mathrm{~K}$, which resulted in 
formation of fixed/stabilized Ce sites on the support and then the Pt precursor was added. Probably, this has caused a decreased Pt-Ce interaction during preparation, which may be an explanation for lower activity levels and poor stability profiles. On the other hand, coimpregnation of $\mathrm{Pt}$ and $\mathrm{Ce}$ precursors together onto the $\mathrm{ZrO}_{2}$ surface and subsequent high temperature thermal treatment (calcination and reduction at $773 \mathrm{~K}$ ) led to strong and extensive Pt-Ce surface interaction, which resulted in the formation of $\mathrm{Ce}^{3+}$ sites. Increased number of oxygen vacancies, which act as oxygen buffer when going through $\mathrm{Ce}^{4+} / \mathrm{Ce}^{3+}$ redox cycle, led to enhanced cleaning ability of surface from deposited carbon, produced on Pt via C$\mathrm{H}$ bond breakage during reaction. The XPS analysis clearly showed that the intensive interaction between Pt and Ce for coimpregnated sample, starting from their precursor states till the metallic and oxide states during calcination and reduction, led to a higher amount of $\mathrm{Ce}^{3+}$ while suppressing the amount of $\mathrm{Pt}^{0}$. This results in higher DR activity of coimpregnated sample, which stems from enhanced oxygen transfer from Ce to Pt. Thus, Pt sites of coimpregnated sample have higher rate of oxygen transfer from $\mathrm{CeO}_{x}$ compared to carbon formation rate on them during the reaction, and, as a consequence, have higher DR activity and stability.

This phenomenon could be also enhanced by the higher dispersion of Pt on the surface of the catalyst, which leads to an increase in the metal-support interface area, favoring the removal of carbon from metal, as well as, the increase in catalytic activity. Tiernan and Finlayson [52] have reported for $\mathrm{Al}_{2} \mathrm{O}_{3}$ supported catalysts that the presence of $\mathrm{Ce}^{3+}$ sites enhances the dispersion of Pt. Although Pt or Ce particle sizes are not detectable with the SEM used in this study, a relatively indirect intuition regarding the dispersion can be gained through considering the micro-scale EDX mapping results and EDX quantification analysis. The results of SEM-EDX studies imply that $1 \mathrm{wt}$ \% $\mathrm{Ce}$ to the $\mathrm{Pt} / \mathrm{ZrO}_{2}$ catalyst via coimpregnation method (cat2) has higher dispersion and small particle sizes of Pt compared to $1 \mathrm{wt} \% \mathrm{Pt}-1 \mathrm{wt} . \% \mathrm{Ce} / \mathrm{ZrO}_{2}$ catalyst prepared by sequential impregnation (cat4). To sum up, we can conclude that coimpregnation of $\mathrm{Pt}$ and Ce together onto $\mathrm{ZrO}_{2}$ surface and subsequent high temperature thermal treatment (calcination and reduction at $773 \mathrm{~K}$ ) have led to strong and extensive Pt-Ce surface interaction, which resulted in the formation of $\mathrm{Ce}^{3+}$ sites and that the presence of $\mathrm{Ce}^{3+}$ sites enhanced the dispersion of Pt.

In accordance with the above discussion, the deactivation of the $1 \mathrm{wt} . \% \mathrm{Pt}-1 \mathrm{wt} . \% \mathrm{Ce} / \mathrm{ZrO}_{2}$ catalyst prepared by sequential impregnation (cat4) would be related to the limited interaction between Pt-Ce precursors during sequential impregnation, which have created insufficient number of oxygen vacant $\mathrm{Ce}^{3+}$ sites, as explained in the above sections. Probably, the production rate of oxygen species on the support - or on the metal/ support boundary - during the $\mathrm{CO}_{2}$ activation process was not high enough to oxidize all carbonaceous species formed on the metal sites; thus, the coke deposition led by insufficient rate of cleaning inhibited the reaction. Parallel to our explanation, many groups have mentioned that the balance between the rate of decomposition and the rate of cleaning determines the overall stability of the catalyst $[5,13,19,20,22]$.

On the other hand; for the other coimpregnated sample, cat3, increasing the loading of Ce from 1 to $5 \mathrm{wt}$ \% resulted in a decrease in the activity of the catalyst at high temperatures, which may be explained by decreased Pt dispersion. According to the work of Tiernan and Finlayson [52], the addition of cerium to $\mathrm{Pt} / \mathrm{Al}_{2} \mathrm{O}_{3}$, particularly at higher levels, results in decreased Pt dispersion. Another reason for the deteriorated activities may be the sintering and encapsulation of Pt particles by high amounts of bulk cerium particles, which may lead to a decrease in the adsorption sites on the metal surface areas as well as in the interfacial region $[53,54]$.

At the end of 4 th hour of TOS, it is observed that the catalysts prepared by coimpregnation method (cat2 and cat3) only lost $4 \%$ of their $\mathrm{CH}_{4}$ activity. This shows the beneficial effect of $\mathrm{Ce}$ addition by coimpregnation method on the overall stability. Addition of cerium improved the amount of surface oxygen through reduction/oxidation cycle of $\mathrm{CeO}_{x}$ and the reducibility of the oxide support; this combined effect enhances the longterm activity and stability of the catalyst. As explained above, coimpregnated samples have higher oxygen transfer rates from $\mathrm{CeO}_{x}$ sites and thus, they do not suffer from activity loss due to carbon deposition. The oxygen vacancies at the metaloxide interface of reduced ceria, leading to high oxygen storage capacity, suppress coke formation. The higher amount of mobile surface oxygen results in an enhanced capability to clean the carbon that would normally accumulate on the metal during the decomposition of $\mathrm{CH}_{4}$. This cleaning ability is also reflected on the total amount of carbon deposits observed by TPO. Moreover, a higher degree of reduction results in an increase in the number of oxygen vacancies formed near the metal particle and a subsequent increase in the ability to dissociate $\mathrm{CO}_{2}$ [5]. For the 1 wt.\%Ce-doped $\mathrm{Pt} / \mathrm{ZrO}_{2}$, the increase in the dissociation ability and subsequent cleaning capacity results in a catalyst with enhanced activity and stability for the $\mathrm{CO}_{2}$ reforming reaction. However, increasing the Ce loading from 1 wt. $\%$ to 5 wt.\% did not have a significant improvement on the stability.

However; unlike the results at $\mathrm{CH}_{4} / \mathrm{CO}_{2}=1.0$, it is observed that $1 \mathrm{wt} . \% \mathrm{Pt}-5 \mathrm{wt} \% \mathrm{Ce} / \mathrm{ZrO}_{2}$ catalyst prepared by coimpregnation method (cat3) displayed the most favorable stability profile at $\mathrm{CH}_{4}: \mathrm{CO}_{2}=2: 1$ case due to its relatively low conversion level at the beginning of the reaction. Addition of higher amount of ceria resulted in an increase in the oxygen storage capacity of the support, as has been shown for different $\mathrm{CeO}_{2}$-containing systems [31]. The cleaning of coke formed becomes more important than the original DR activity for cat3 when the reaction condition is severe, like $\mathrm{CH}_{4}: \mathrm{CO}_{2}=2: 1$ case. This result is also supported with the lower activation energy of $1 \mathrm{wt} . \% \mathrm{Pt}-5 \mathrm{wt} . \% \mathrm{Ce} / \mathrm{ZrO}_{2}$ catalyst prepared by coimpregnation method (cat3) for $\mathrm{CO}_{2}$ consumption, which may explain the higher dissociative $\mathrm{CO}_{2}$ adsorption ability of cat3. Likewise, insignificant amount of coke deposition detected as an outcome of TPO tests after the reaction also validates the relatively stable behavior of cat3 under high $\mathrm{CH}_{4} / \mathrm{CO}_{2}$ feed ratio.

\section{Conclusions}

$\mathrm{DR}$ of methane has been studied over $\mathrm{Pt} / \mathrm{ZrO}_{2}$ catalysts promoted with Ce using different impregnation strategies and cerium amounts. Use of cerium was found to be potentially 
beneficial for $\mathrm{CO}_{2}$ reforming of methane activity of $\mathrm{Pt} / \mathrm{ZrO}_{2}$. The effects of the Ce on catalyst activity depended on the cerium loading used and impregnation strategy. Introduction of $1 \mathrm{wt} . \% \mathrm{Ce}$ to the $\mathrm{Pt} / \mathrm{ZrO}_{2}$ catalyst via coimpregnation method led to superior catalytic activities and stabilities. The catalyst displayed a significant improvement in the $\mathrm{H}_{2} / \mathrm{CO}$ ratio; $\mathrm{H}_{2} / \mathrm{CO}$ ratio tends to unity at high temperatures. Coimpregnation of $\mathrm{Pt}$ and $\mathrm{Ce}$ together onto $\mathrm{ZrO}_{2}$ surface and subsequent high temperature thermal treatment (calcination and reduction at $773 \mathrm{~K}$ ) have led to strong and extensive $\mathrm{Pt}-\mathrm{Ce}$ surface interaction, which produced the formation of $\mathrm{Ce}^{3+}$ sites and that the presence of $\mathrm{Ce}^{3+}$ sites enhanced the dispersion of Pt. Under normal reaction conditions, increasing the loading of Ce from $1 \mathrm{wt} . \%$ to $5 \mathrm{wt}$ \% resulted in a decrease in the catalytic activity of catalysts at high temperature. Under severe reaction conditions, like $\mathrm{CH}_{4}: \mathrm{CO}_{2}=2: 1$ case, it is observed that $1 \mathrm{wt} . \% \mathrm{Pt}-5 \mathrm{wt} . \% \mathrm{Ce} / \mathrm{ZrO}_{2}$ catalyst prepared by coimpregnation method (cat3) displayed the most favorable stability profile.

\section{Acknowledgements}

This study has been supported by Boğaziçi University through the projects DPT-07K120630, DPT-03K120250 and BAP06A506D.

A. Erhan Aksoylu acknowledges financial support by TÜBA-GEBIP program. Emrah Özensoy acknowledges "The Scientific and Technological Research Council of Turkey (TÜBITAK)" for financial support (Project Codes: $105 Y 260$ and 107Y115).

\section{R E F E R E N C E S}

[1] Therdthianwong S, Therdthianwong A, Siangchin C, Yongprapat S. Synthesis gas production from dry reforming of methane over $\mathrm{Ni} / \mathrm{Al}_{2} \mathrm{O}_{3}$ stabilized by $\mathrm{ZrO}_{2}$. Int $\mathrm{J}$ Hydrogen Energy 2008;33:991-9.

[2] $\mathrm{He} \mathrm{S}, \mathrm{Wu} \mathrm{H}, \mathrm{Yu} \mathrm{W}, \mathrm{Mo}$ L, Lou $\mathrm{H}$, Zheng X. Combination of $\mathrm{CO}_{2}$ reforming and partial oxidation of methane to produce syngas over $\mathrm{Ni} / \mathrm{SiO}_{2}$ and $\mathrm{Ni}-\mathrm{Al}_{2} \mathrm{O}_{3} / \mathrm{SiO}_{2}$ catalysts with different precursors. Int J Hydrogen Energy 2009;34:839-43.

[3] Verykios XE. Catalytic dry reforming of natural gas for the production of chemicals and hydrogens. Int J Hydrogen Energy 2003;28:1045-63.

[4] Bradford MCJ, Vannice MA. $\mathrm{CO}_{2}$ reforming of $\mathrm{CH}_{4}$ over supported Pt catalysts. J Catal 1998;173:157-71.

[5] Stagg-Williams SM, Noronha FB, Fendley G, Resasco DE. $\mathrm{CO}_{2}$ reforming of $\mathrm{CH}_{4}$ over $\mathrm{Pt} / \mathrm{ZrO}_{2}$ catalysts promoted with $\mathrm{La}$ and Ce oxides. J Catal 2000;194:240-9.

[6] Ballarini AD, Miguel SR, Jablonski EL, Scelza OA, Castro AA. Reforming of $\mathrm{CH}_{4}$ with $\mathrm{CO}_{2}$ on Pt-supported catalysts: effect of the support on the catalytic behaviour. Catal Today 2005; 107-108:481-6.

[7] Djaidja A, Libs S, Keinnemann A, Barama A. Characterization and activity in dry reforming of methane on $\mathrm{NiMg} / \mathrm{Al}$ and Ni/MgO catalysts. Catal Today 2006;113:194-200.

[8] Nagaoka K, Seshan K, Aika K, Lercher JA. Carbon deposition during carbon dioxide reforming of methane - comparison between $\mathrm{Pt} / \mathrm{Al}_{2} \mathrm{O}_{3}$ and $\mathrm{Pt} / \mathrm{ZrO}_{2}$. J Catal 2001;197:34-42.
[9] Guo J, Lou H, Zhao H, Chai D, Zheng X. Dry reforming of methane over nickel catalysts supported on magnesium aluminate spinels. Appl Catal A 2004;273:75-82.

[10] Hou Z, Yokota O, Tanaka T, Yashima T. Surface properties of a coke-free Sn doped nickel catalyst for the $\mathrm{CO}_{2}$ reforming of methane. Appl Surf Sci 2004;233:58-68.

[11] Ferreira-Aparicio P, Guerrero-Ruiz A, Rodríguez-Rammos I. Comparative study at low and medium reaction temperatures of syngas production by methane reforming with carbon dioxide over silica and alumina supported catalysts. Appl Catal A 1998;170:177-87.

[12] Montoya JA, Romero-Pascual E, Gimon C, Del Angel P, Monzón A. Methane reforming with $\mathrm{CO}_{2}$ over $\mathrm{Ni} / \mathrm{ZrO}_{2}-\mathrm{CeO}_{2}$ catalysts prepared by sol-gel. Catal Today 2000;63:71-85.

[13] Nagaoka K, Okamura M, Aika K. Titania supported ruthenium as a coking-resistant catalyst for high pressure dry reforming of methane. Catal Commun 2001;2:255-60.

[14] Bradford MCJ, Vannice MA. $\mathrm{CO}_{2}$ reforming of $\mathrm{CH}_{4}$. Catal RevSci Eng 1999;41:1-42.

[15] Menad S, Ferreira-Aparicio P, Cherifi O, Guerrero-Ruiz A, Rodríguez-Ramos I. Designing new high oxygen mobility supports to improve the stability of Ru catalysts under dry reforming of methane. Catal Lett 2003;89:63-7.

[16] Wang HY, Ruckenstein E. Carbon dioxide reforming of methane to synthesis gas over supported rhodium catalysts: the effect of support. Appl Catal A 2000;204:143-52.

[17] Efstathiou AM, Kladi A, Tsipouriari VA, Verykios XE. Reforming of methane with carbon dioxide to synthesis gas over supported rhodium catalysts: II. A steady-state tracing analysis: mechanistic aspects of the carbon and oxygen reaction pathways to form CO. J Catal 1996;158:64-75.

[18] Ferreira-Aparicio P, Rodriguez-Rammos I, Anderson JA, Guerrero-Ruiz A. Mechanistic aspects of the dry reforming of methane over ruthenium catalysts. Appl Catal A 2000;202: 183-96.

[19] Slagtern A, Schuurman Y, Leclercq C, Verykios X, Mirodatos C. Specific features concerning the mechanism of methane reforming by carbon dioxide over $\mathrm{Ni} / \mathrm{La}_{2} \mathrm{O}_{3}$ catalyst. J Catal 1997;172:118-26.

[20] Zhang Z, Verykios XE, Macdonald SM, Affrossman S. Comparative study of carbon dioxide reforming of methane to synthesis gas over $\mathrm{Ni} / \mathrm{La}_{2} \mathrm{O}_{3}$ and conventional nickelbased catalysts. J Phys Chem 1996;100:744-54.

[21] Nagaoka K, Seshan K, Lercher JA, Aika K. Activation mechanism of methane-derived coke $\left(\mathrm{CH}_{\mathrm{x}}\right)$ by $\mathrm{CO}_{2}$ during dry reforming of methane - comparison for $\mathrm{Pt} / \mathrm{Al}_{2} \mathrm{O}_{3}$ and $\mathrm{Pt} / \mathrm{ZrO}_{2}$. Catal Lett 2000;70:109-16.

[22] Bitter JH, Seshan K, Lercher JA. The state of zirconia supported platinum catalysts for $\mathrm{CO}_{2} / \mathrm{CH}_{4}$ reforming. J Catal 1997;171:279-86.

[23] Stagg SM, Romero E, Padro C, Resasco DE. Effect of promotion with $\mathrm{Sn}$ on supported Pt catalysts for $\mathrm{CO}_{2}$ reforming of $\mathrm{CH}_{4}$. J Catal 1998;178:137-45.

[24] Mattos LV, Rodino E, Resasco DE, Passos FB, Noronha FB. Partial oxidation and $\mathrm{CO}_{2}$ reforming of methane on $\mathrm{Pt} / \mathrm{Al}_{2} \mathrm{O}_{3}$, $\mathrm{Pt} / \mathrm{ZrO}_{2}$, and $\mathrm{Pt} / \mathrm{Ce}-\mathrm{ZrO}_{2}$ catalysts. Fuel Process Technol 2003; 83:147-61.

[25] Wang W, Stagg-Williams SM, Noronha FB, Mattos LV, Passos FB. Partial oxidation and combined reforming of methane on Ce-promoted catalysts. Catal Today 2004;98: 553-63.

[26] Alvarez-Galvan MC, Navarro RM, Rosa F, Briceño Y, Gordillo Alvarez F, Fierro JLG. Performance of La, Ce-modified alumina-supported Pt and Ni catalysts for the oxidative reforming of diesel hydrocarbons. Int J Hydrogen Energy 2008;33:652-63.

[27] Sohier MP, Wrobel G, Bonnelle JP, Marcq JP. Hydrogenation catalysts based on nickel and rare earths oxides: I. Relation 
between cations nature, preparation route, hydrogen content and catalytic activity. Appl Catal A 1992;84:169-86.

[28] Son IH, Lane AM. Promotion of $\mathrm{Pt} / \gamma-\mathrm{Al}_{2} \mathrm{O}_{3}$ by Ce for preferential oxidation of $\mathrm{CO}$ in $\mathrm{H}_{2}$. Catal Lett 2001;76:151-4.

[29] Farrauto RJ, Heck RM. Catalytic converters: state of the art and perspectives. Catal Today 1999;51:351-60.

[30] Kašpar J, Fornasiero P, Graziani M. Use of $\mathrm{CeO}_{2}$-based oxides in the three-way catalysis. Catal Today 1999;50:285-98.

[31] Kozlov AI, Kim DH, Yezerets A, Anderson P, Kung HH, Kung MC. Effect of preparation method and redox treatment on the reducibility and structure of supported ceria-zirconia mixed oxide. J Catal 2002;209:417-26.

[32] Damyanova S, Bueno JMC. Effect of $\mathrm{CeO}_{2}$ loading on the surface and catalytic behaviors of $\mathrm{CeO}_{2}-\mathrm{Al}_{2} \mathrm{O}_{3}$-supported Pt catalysts. Appl Catal A 2003;253:135-50.

[33] Trovarelli A. Catalytic properties of ceria and $\mathrm{CeO}_{2}$ containing materials. Catal Rev-Sci Eng 1996;38:439-520.

[34] Holmgren A, Andersson B. Oxygen storage dynamics in $\mathrm{Pt} / \mathrm{CeO}_{2} / \mathrm{Al}_{2} \mathrm{O}_{3}$ catalysts. J Catal 1998;178:14-25.

[35] Bozo C, Guilhaume N, Garbowski E, Primet M. Combustion of methane on $\mathrm{CeO}_{2}-\mathrm{ZrO}_{2}$ based catalysts. Catal Today 2000;59: 33-45.

[36] Passos FB, Oliveira ER, Mattos LV, Noronha FB. Partial oxidation of methane to synthesis gas on $\mathrm{Pt} / \mathrm{Ce}_{x} \mathrm{Zr}_{1-x} \mathrm{O}_{2}$ catalysts: the effect of the support reducibility and of the metal dispersion on the stability of the catalysts. Catal Today 2005;101:23-30.

[37] Querino PS, Bispo JRC, Rangel MC. The effect of cerium on the properties of $\mathrm{Pt} / \mathrm{ZrO}_{2}$ catalysts in the WGSR. Catal Today 2005;107-108:920-5.

[38] Jung KT, Bell AT. The effects of synthesis and pretreatment conditions on the bulk structure and surface properties of zirconia. J Mol Catal A: Chem 2000;163:27-42.

[39] Serrano-Ruiz JC, Luettich J, Sepúlveda-Escribano A, Rodríguez-Reinoso F. Effect of the support composition on the vapor-phase hydrogenation of crotonaldehyde over $\mathrm{Pt} / \mathrm{Ce}_{x} \mathrm{Zr}_{1-x} \mathrm{O}_{2}$ catalysts. J Catal 2006;241:45-55.

[40] Shyu JZ, Otto K. Identification of platinum phases on $\gamma$-alumina by XPS. Appl Surf Sci 1988;32:246-52.

[41] Serre C, Garin F, Belot G, Maire G. Reactivity of $\mathrm{Pt} / \mathrm{Al}_{2} \mathrm{O}_{3}$ and $\mathrm{Pt}-\mathrm{CeO}_{2} \mathrm{Al}_{2} \mathrm{O}_{3}$ catalysts for the oxidation of carbon monoxide by oxygen: I. Catalyst characterization by TPR using $\mathrm{CO}$ as reducing agent. J Catal 1993;141:1-8.
[42] Burroughs P, Hammett A, Orchard AF, Thornton G. Satellite structure in X-ray photoelectron-spectra of some binary and mixed oxides of lanthanum and cerium. J Chem Soc Dalton Trans 1976;17:1686-98.

[43] Romeo M, Bak K, El Fallah J, Le Normand F, Hilaire L. XPS study of the reduction of cerium dioxide. Surf Interf Anal 1993;20:508-12.

[44] Laachir A, Perrichon V, Badri A, Lamotte J, Catherine E, Lavalley JC, et al. Reduction of $\mathrm{CeO}_{2}$ by hydrogen-Magneticsusceptibility and Fourier-transform infrared, ultraviolet and $\mathrm{X}$-ray photoelectron-spectroscopy measurements. J Chem Soc Faraday Trans 1991;87:1601-9.

[45] Silvestre-Albero J, Rodríguez-Reinoso F, SepúlvedaEscribano A. Improved metal-support interaction in $\mathrm{Pt} / \mathrm{CeO}_{2} /$ $\mathrm{SiO}_{2}$ catalysts after zinc addition. J Catal 2002;210:127-36.

[46] Shyu JZ, Otto K, Watkins WLH, Graham GW, Belitz RK, Gandhi HS. Characterization of $\mathrm{Pd} / \gamma$-alumina catalysts containing ceria. J Catal 1988;114:23-33.

[47] Noronha FB, Fendley EC, Soares RR, Alvarez WE, Resasco DE. Correlation between catalytic activity and support reducibility in the $\mathrm{CO}_{2}$ reforming of methane over $\mathrm{Pt} / \mathrm{Ce}_{\mathrm{x}} \mathrm{Zr}_{1-x} \mathrm{O}_{2}$ catalysts. Chem Eng J 2001;82:21-31.

[48] Kotani A, Jo T, Parlebas JC. Many-body effects in core-level spectroscopy of rare-earth compounds. Adv Phys 1989;37: 37-85.

[49] Ernst B, Hilaire L, Kiennemann A. Effects of highly dispersed ceria addition on reducibility, activity and hydrocarbon chain growth of a $\mathrm{Co} / \mathrm{SiO}_{2}$ Fischer-Tropsch catalyst. Catal Today 1999;50:413-27.

[50] Paparazzo E. XPS studies of damage induced by X-rayirradiation on $\mathrm{CeO}_{2}$ surfaces. Surf Sci 1990;234:L253-8.

[51] Yang M, Papp H. $\mathrm{CO}_{2}$ reforming of methane to syngas over highly active and stable Pt/MgO catalysts. Catal. Today 2006; 115:199-204.

[52] Tiernan MJ, Finlayson OE. Effects of ceria on the combustion activity and surface properties of $\mathrm{Pt} / \mathrm{Al}_{2} \mathrm{O}_{3}$ catalysts. Appl Catal B 1998;19:23-35.

[53] Fan J, Wu X, Ran R, Weng D. Influence of the oxidative/ reductive treatments on the activity of $\mathrm{Pt} / \mathrm{Ce}_{0.67} \mathrm{Zr}_{0.33} \mathrm{O}_{2}$ catalyst. Appl Surf Sci 2005;245:162-71.

[54] Fan J, Wu X, Yang L, Weng D. The SMSI between supported platinum and $\mathrm{CeO}_{2}-\mathrm{ZrO}_{2}-\mathrm{La}_{2} \mathrm{O}_{3}$ mixed oxides in oxidative atmosphere. Catal Today 2007;126:303-12. 